\title{
INVESTIGATION OF THE STRUCTURE AND PROPERTIES OF CERAMIC MATERIALS WITH A RIGID SYSTEM OF MICROFILTRATION TRANSPORT PORES BASED ON BASALT FIBERS
}

\author{
Dr., Prof. E. E. Petyushik ${ }^{3}$, Dr., Prof. S. M. Azarov ${ }^{2}$, Ph.d. T. A. Azarova ${ }^{2}$, S. V. Besarab ${ }^{3}$, Ph.d., \\ Associate Professor A. A. Drobysh ${ }^{2}, Y u$. D. Sauka ${ }^{3}$ \\ 1. State Scientific and Production Association of Powder Metallurgy, Republic of Belarus \\ 2. Belarusian National Technical University, Minsk, Republic of Belarus \\ 3. Institute of General and Inorganic Chemistry of the National Academy of Sciences of Belarus, Minsk, \\ Republic of Belarus
}

The report provides information on the formation of the structure of porous ceramic materials made of basalt fiber obtained by pressing with subsequent sintering. The phase composition, structure, and properties of ceramics are studied. The relationship between the structure, phase composition, and properties of the ceramic material is established.

Keywords: basalt, fiber, iron oxides, aluminosilicates, material properties, structure, phase composition, permeability, porosity

\section{Introduction}

The use of porous materials based on ceramic fibers for the manufacture of filter elements, dispersants, fire barriers, catalytic elements, etc. is relevant, due to the possibility of their operation at high thermal loads. The interest in the use of basalt fiber for the production of technical ceramics is based on the possibility of forming a fibrous matrix that has not only high permeability, but also significant strength. In works 1, 2, the features of the structure formation of materials based on basalt fiber are studied; the influence of molding modes, heat treatment and technological properties of the charge on the frame and structural characteristics of porous samples is established. The ranges of the obtained characteristics are quite large: pore sizes can vary within 2.7-16 microns, compressive strength $-0.2-2.1 \mathrm{MPa}$, permeability can reach $(2-9) \times 10-{ }^{10} \mathrm{~m}^{2}$. The main difficulty in obtaining ceramic materials with a rigid system.

Ceramics based on dispersed fibers are characterized by a low specific gravity combined with increased strength, thermal conductivity, and resistance to thermal shocks. Presumably, the creation of porous ceramics from ceramic fibers will add an increase in the permeability coefficient to the above advantages. However, the range of fibers suitable for creating technologically strong ceramics is limited by the properties of the source material. In the production of basalt fibers, rocks are used as raw materials, the chemical composition of which is similar in composition to aluminosilicate powders (\% by weight): $\mathrm{SiO}_{2}$ (47.5-55.0); $\mathrm{Al}_{2} \mathrm{O}_{3}$ (14.0-20.0). As it was previously proved, sintering of such a composition will occur with the participation of the liquid phase. Thus, porous materials characterized by a composite structure can be created on the basis of a fibrous matrix - composite porous materials. Composite porous materials with a rigid system of microfiltration transport pores made of basalt fibers have not been created before.

A distinctive feature of porous materials made of basalt fiber is that the filtering characteristics are regulated not only by the volume ratio of the basalt matrix and the material for the formation of pores, but also by the nature of the mutual arrangement of the fibers, which is determined by the technological modes of forming the product, as well as the ratio and structure of the initial components. In contrast to the known woven materials (fiber basalt slabs), the size and configuration of the pores of the created porous materials remain constant during operation due to the rigidity of the frame. 
Such a technical solution makes it possible to improve the quality of water, air, and other media purification and radically reduce the dimensions of filter devices while reducing regeneration costs by replacing filter materials operating in the volume filtration mode with filter elements, in which the removed impurities are collected on the surface of the filter partition. In this case, particles larger than the pores are retained, and then a layer of impurities is formed from them, which is also a filter material. The process is typical for a rigid porous partition with a thickness of $1 \ldots 20 \mathrm{~mm}$, with pore sizes of $1 \ldots 20$ microns (microfiltration mode), organized in the form of plates or pipes of various diameters (filter elements) that operate at low filtration speeds. If the filtration speeds are usually $10 \ldots 25 \mathrm{~m} / \mathrm{h}$ during the operation of granular loads, then the filtration speeds in the microfiltration mode should not exceed $5 \mathrm{~m} / \mathrm{h}$. The dirt accumulated on the filter surface is periodically removed into the drainage by backwashing with filtered water.

The aim of the study is structural-phase transformations during the formation of a porous material by sintering basalt fibers and establishing the conditions for the interaction of fiber dispersed systems that allow creating a regular pore structure

\section{Methods, materials and results of the experiment}

The studies were carried out on samples in the form of pipes $\varnothing 65 \mathrm{~mm}$, up to $500 \mathrm{~mm}$ long, formed by radial pressing at a pressure of $40 \mathrm{MPa}$ and sintered from basalt fiber in air at 1000 , $1050,1100^{\circ} \mathrm{C}$. The type of samples and the structure of the porous material are shown in Fig. 1. The compressive strength was determined on samples $\varnothing 17 \mathrm{~mm}, 10-17 \mathrm{~mm}$ high, formed in a mold at a pressure of $40 \mathrm{MPa}$.

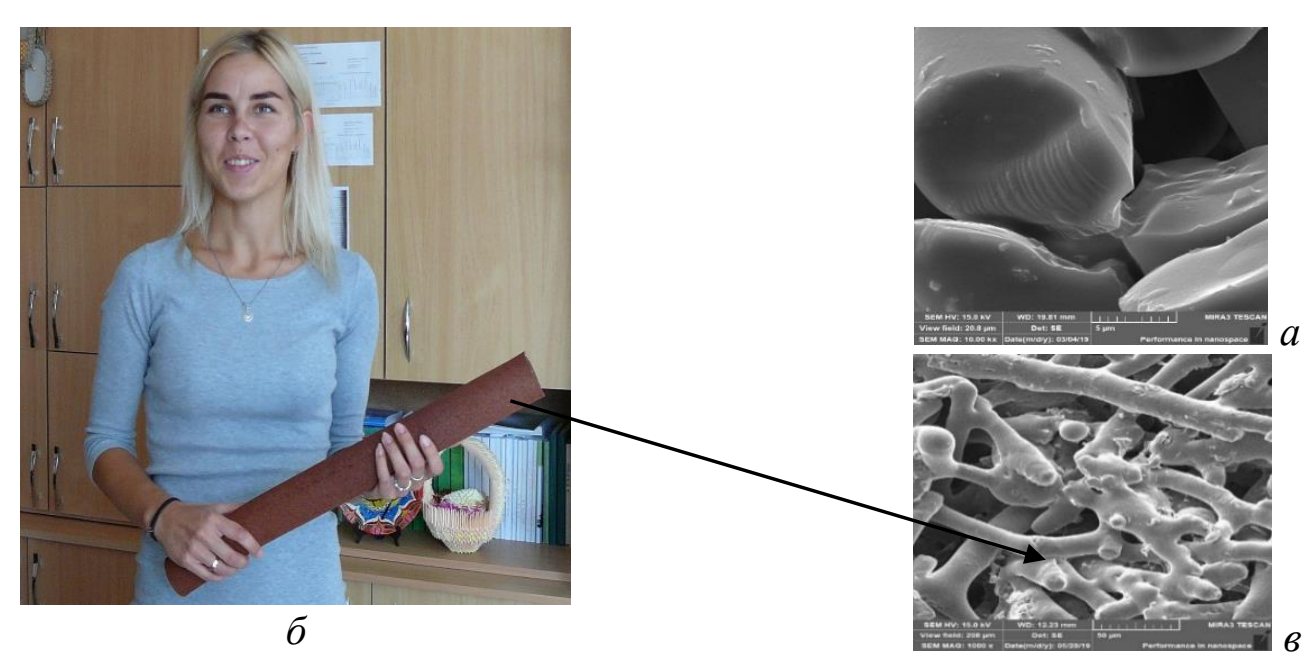

Fig. 1. Type of samples: $a$ - basalt fiber; $b-a$ filter element made of basalt fiber in the hands of a master student; $\mathrm{c}$ - the structure of a porous material

To determine the heat resistance, the samples were heated in air in a SNOL furnace to temperatures from $1000,1050,1100^{\circ} \mathrm{C}$, followed by sharp cooling in water, oil or liquid nitrogen and drying at room temperature for a day. The criterion for assessing the heat resistance was the ability of the samples to maintain compressive strength. 
The strength, porosity, differential thermal, X-ray spectral and X-ray phase analyses, as well as the morphology of the surface of the materials under consideration were studied according to standard methods in the Department of Research and Testing of materials (accreditation certificate VU/112 1.0263) of the State Research University "Institute of Powder Metallurgy named after O. V. Roman". The phase composition and properties of the initial samples of porous materials made of basalt fiber sintered at different temperatures are shown in Tables 1, 2.

After sintering, the samples were cooled to room temperature, then in batches of 5 pieces they were heated to certain temperatures and quickly immersed in a quenching medium.

Table 1. Phase composition of a porous material made of basalt fiber sintered at $1050{ }^{\circ} \mathrm{C}$

\begin{tabular}{|c|c|c|c|}
\hline \multicolumn{4}{|c|}{ Crystal phase (formula), wt.\% } \\
\hline $\begin{array}{c}\text { Anorthite } \\
\left(\mathrm{CaAl}_{2} \mathrm{Si}_{2} \mathrm{O}_{8}\right)\end{array}$ & $\begin{array}{c}\text { Andradite } \\
\left(\mathrm{Ca}_{3} \mathrm{Fe}_{2}\left(\mathrm{Si}_{3} \mathrm{O}_{12}\right)\right)\end{array}$ & $\begin{array}{c}\text { Silicon Oxide } \\
\left(\mathrm{SiO}_{2}\right)\end{array}$ & $\begin{array}{c}\text { Potassium-aluminosilicate spinelide } \\
\left(\mathrm{K}_{0.85} \mathrm{Al}_{0.85} \mathrm{Si}_{0.15} \mathrm{O}_{2}\right)\end{array}$ \\
\hline 65 & 9 & 14 & 11 \\
\hline
\end{tabular}

Table 2. Properties of basalt fiber samples depending on the sintering temperature

\begin{tabular}{|c|c|c|c|c|}
\hline \multirow{2}{*}{$\begin{array}{c}\text { Sintering } \\
\text { temperature, }\end{array}$} & \multicolumn{4}{|c|}{$\mathrm{C}$} \\
\cline { 2 - 5 } & $\begin{array}{c}\text { Compressive } \\
\text { strength, } \mathrm{MPa}\end{array}$ & $\begin{array}{c}\text { Density, } \\
\mathrm{g} / \mathrm{sm}^{3}\end{array}$ & $\begin{array}{c}\text { Specific } \\
\text { surface } \text { area, }^{2} / \mathrm{g}\end{array}$ & $\begin{array}{c}\text { Permeability, } \\
10^{-10} \mathrm{~m}^{2}\end{array}$ \\
\hline 1000 & $1,0-1,1$ & $0,61-0,65$ & $0,425-0,655$ & $6-8$ \\
\hline 1050 & $1,6-1,8$ & $0,79-0,87$ & $0,165-0,225$ & $4-6$ \\
\hline 1100 & $2,2-2,5$ & $0,89-0,93$ & $0,115-0,135$ & $2-4$ \\
\hline
\end{tabular}

*- the number of samples in each series is not less than 5

The structure shown in Fig. 1b allows us to assume that almost all the pores of the studied material are open, therefore, with an average basalt density of $3 \mathrm{~g} / \mathrm{cm} 3$ and a density of the studied material of $0.6-0.9 \mathrm{~g} / \mathrm{cm} 3$ (Table. 2) the sample porosity can be considered equal to $65-80 \%$. Comparative characteristics of samples of porous materials, as well as their processing modes are given in Table. 3. The correlation coefficient when determining the specific surface area for samples from batches $1,3-5$ was $0.71-0.94$. For the samples of batch 2 , it was in the range of $0.26-0.28$.

Table 3. Heat treatment conditions and comparative characteristics of samples of porous materials sintered at $1050{ }^{\circ} \mathrm{C}$ after quenching

\begin{tabular}{|c|c|c|c|c|c|c|c|}
\hline \multirow{2}{*}{$\begin{array}{c}\text { Series } \\
\text { No. }\end{array}$} & \multicolumn{2}{|c|}{ Processing conditions } & \multicolumn{5}{|c|}{$\begin{array}{c}\text { Characteristics of the samples } \\
\text { temperature, } \\
{ }^{\circ} \mathrm{C}\end{array}$}
\end{tabular}

* - before heating, the samples were kept in water for 24 hour 
As follows from the results presented in Table 3, the density of the material is practically constant for all samples, therefore, the porosity after quenching did not change. It was found that the quenching medium does not affect the composition of the porous material presented in Table 4 , changing the phase ratio to a small extent.

Table 4. Phase composition of a porous material made of basalt fiber sintered at $1050{ }^{\circ} \mathrm{C}$, after quenching

\begin{tabular}{|c|c|c|c|}
\hline \multicolumn{4}{|c|}{ Crystal phase (formula), wt.\%, mac.\% } \\
\hline $\begin{array}{c}\text { Anorthite } \\
\left(\mathrm{CaAl}_{2} \mathrm{Si}_{2} \mathrm{O}_{8}\right)\end{array}$ & $\begin{array}{c}\text { Hematite } \\
\left(\mathrm{Fe}_{2} \mathrm{O}_{3}\right)\end{array}$ & $\begin{array}{c}\text { Silicon Oxide } \\
\left(\mathrm{SiO}_{2}\right)\end{array}$ & $\begin{array}{c}\text { Potassium-aluminosilicate spinelide } \\
\left(\mathrm{K}_{0.85} \mathrm{Al}_{0.85} \mathrm{Si}_{0.15} \mathrm{O}_{2}\right)\end{array}$ \\
\hline 73 & 9 & 12 & 6 \\
\hline
\end{tabular}

The microstructure of the surface of porous materials made of basalt fiber, sintered at $1050{ }^{\circ} \mathrm{C}$, before and after quenching in various media is shown in Fig. 2.

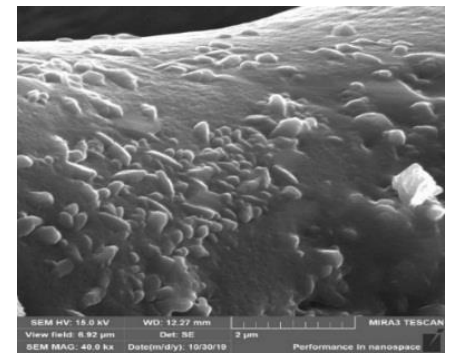

$a$

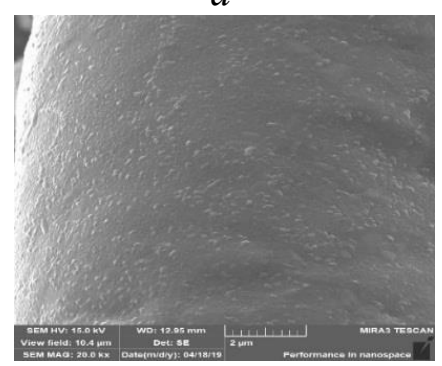

B

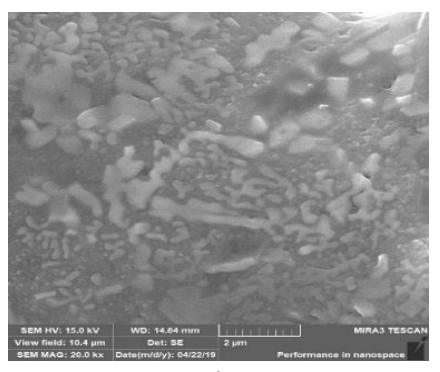

$\partial$

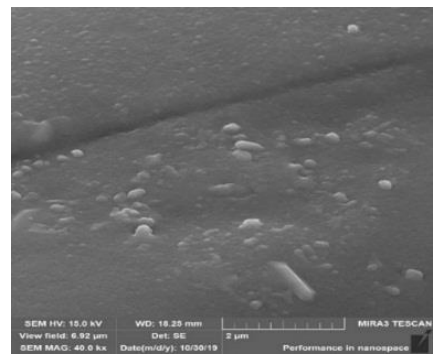

6

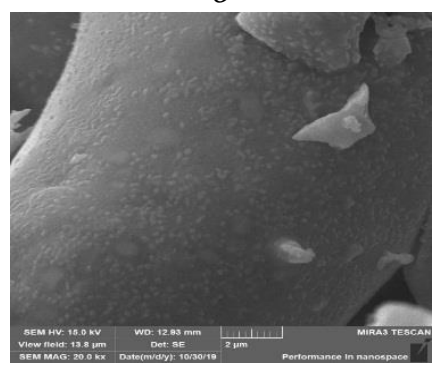

2

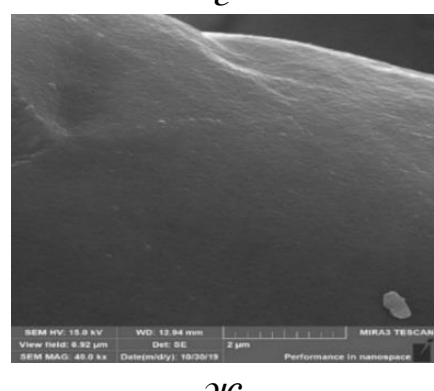

Ж

Fig. 2. Microstructure of the surfaces of the studied materials made of basalt fiber before (w) and after quenching in different media: a $800800{ }^{\circ} \mathrm{C}$, liquid nitrogen; b-500 ${ }^{\circ} \mathrm{C}$, liquid nitrogen; $\mathrm{c}-500{ }^{\circ} \mathrm{C}$, water; $\mathrm{d}-500{ }^{\circ} \mathrm{C}$, oil; $\mathrm{d}-500{ }^{\circ} \mathrm{C}$, liquid nitrogen (a day in water before heat treatment)

The results of microrentgenospectral analysis of the surface of the sample of series 2 (Table. 3) with the image of the studied area are shown in Fig. 3. 


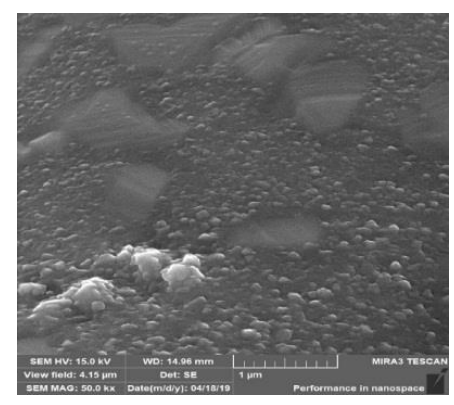

$a$

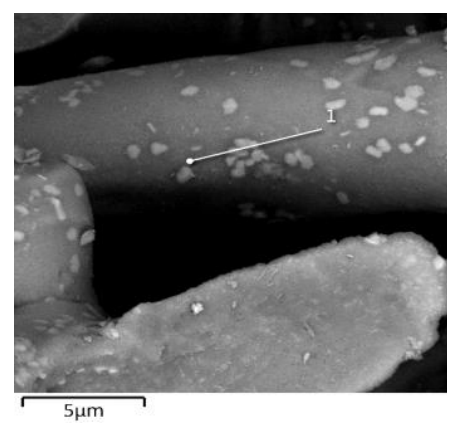

6

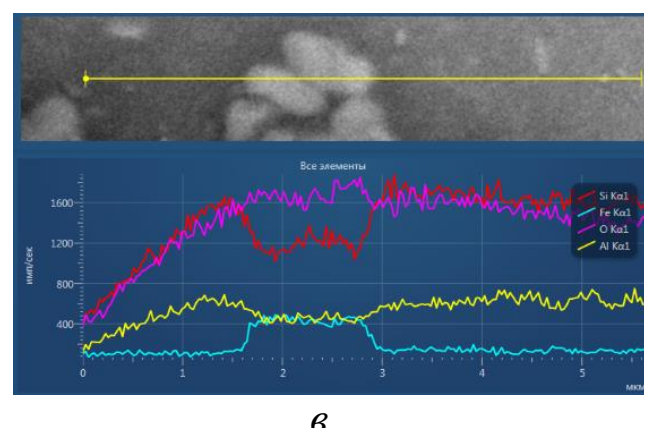

B

Fig. 3. Results of microrentgenospectral analysis with the image of the area of the studied surface of the sample of series $2: a-$ the type of the crystal phase on the surface of the basalt fiber after quenching; $b$ the surface of the fiber with a segment of the MRSA; c-the MRSA curves for the specified elements

It is known that the main mineralogical components of basalt are aluminosilicates-minerals belonging to the groups of pyroxenes and plagioclases, which are solid solutions of variable composition. Iron oxides are mainly included in the composition of magnetite, anorthite, andradite and other minerals [6]. In a number of works [7 - 10], it was found that when basalt fiber is heated above $1000{ }^{\circ} \mathrm{C}$, the destruction of chain silicate structures is observed, accompanied by the formation of a low - molecular iron-containing phase-hematite $\left[\alpha-\mathrm{Fe}_{2} \mathrm{O}_{3}\right]$, and a frame silicate of an isomorphic series. $1000{ }^{\circ} \mathrm{C}$, the destruction of chain silicate structures is observed, accompanied by the formation of a low - molecular-weight iron-containing phase-hematite $\left[\alpha-\mathrm{Fe}_{2} \mathrm{O}_{3}\right]$, and a frame silicate of an isomorphic series.

The thermal properties and crystallization ability of basalt fiber were studied using differential thermal analysis in the air atmosphere. The presence of an inflection at a temperature of $708^{\circ} \mathrm{C}$ is due to the fact that spinelid embryos are formed in the fiber. In the range of $900-1000{ }^{\circ} \mathrm{C}$, conditions for the crystallization of andradite and anorthite are created. At the same time, as indicated in [5], heating above $1000^{\circ} \mathrm{C}$ leads to a decrease in the viscosity of the amorphous fiber matrix and melting of the crystalline phases. Based on the results presented in [8] on the calculation of the crystallization energy of the spinel, pyroxene and plagioclase phases, the most likely result of abrupt cooling is the formation of spinelide. This, in turn, indicates the three-and twodimensional nature of crystal growth on a fixed number of nuclei under sharp cooling [9]. Thus, crystallization in fibers during quenching begins with the formation of potassium-aluminosilicate spinelide nuclei, which act as crystallization centers and are part of the orthoclase structure. The last in the hierarchy of phases is the formation of a low-molecular-weight iron-containing phasehematite $\left[\alpha-\mathrm{Fe}_{2} \mathrm{O}_{3}\right]$, embedded in a frame silicate of an isomorphic series.

The images of the topography of the surface of materials after quenching presented in Fig. 2, 3 and the results of microrentgenospectral analysis confirm the assumptions made. It is seen that when samples heated to temperatures of 500 and $800{ }^{\circ} \mathrm{C}$ are sharply cooled by immersing them in a quenching liquid, areas of the crystalline phase with dimensions of $100500500 \mathrm{~nm}$ are formed on the surface of basalt fibers. The MRSA data presented in Fig. 3 show that an increase in the concentration of iron and oxygen is recorded in the studied zone of the crystalline phase against the background of a significant decrease in the content of silicon and slightly aluminum. Based on the above considerations, the most likely is the formation of a low-molecular-weight ironcontaining phase-hematite $\left[\alpha-\mathrm{Fe}_{2} \mathrm{O}_{3}\right]$, embedded in the frame silicate of an isomorphic series Significant differences in the morphology of the basalt fiber surfaces in porous materials before and after quenching (Fig. 2) determine the differences in the strength and specific surface area of the samples. The results presented in Tables 2, 3 indicate an increase in the strength and specific surface area of porous materials sintered from basalt fiber with subsequent quenching by $2-2.5$ times while maintaining the initial permeability. 
Consequently, the result of the thermal load on the materials under study is an increase in their strength. At the same time, the values of the permeability coefficient and porosity do not undergo significant changes. From the data given in Table 3, it follows that an increase in strength is characteristic for all cooling modes, which may be a consequence of an increase in the degree of crystallinity of the structure as a result of activation of liquation processes in the amorphous fiber matrix in combination with the damping effect of pores and the micron size of the fiber diameter, which allows to reduce the process of cracking.

\section{Main results and conclusions of the work}

1. It is established that the method of radial pressing at $40 \mathrm{MPa}$ and sintering at 1000111100 - With basalt fiber is promising for the manufacture of porous materials. The sequence of phase transformations in basalt fibers under thermal loads is determined. It is established that crystallization in fibers during quenching begins with the formation of potassium-aluminosilicate spinelide nuclei that act as crystallization centers and are part of the orthoclase structure. The last in the hierarchy of phases is the formation of a low-molecular-weight iron-containing phasehematite $\left[\alpha-\mathrm{Fe}_{2} \mathrm{O}_{3}\right]$, embedded in a frame silicate of an isomorphic series.

2. It is shown that as a result of thermal loads on the structure of porous materials made of basalt fiber, the strength indicators increase under all quenching modes. At the same time, the values of the permeability coefficient and porosity do not undergo significant changes. The increase in strength may be a consequence of an increase in the degree of crystallinity of the structure as a result of activation of liquation processes in the amorphous fiber matrix in combination with the damping effect of pores and micron diameters of fibers, which allows to reduce the process of microcrack development.

\section{BIBLIOGRAPHIC LIST}

1. Azarau S. M. "Conditions for the formation of composite porous materials of increased strength based on aluminosilicate powders and basalt fibers" (Message 1)// collection of papers"Powder Metallurgy" vol. 41; p. 90-95.

2. Piatsiushyk Y.Y., Azarau S.M., Drobysh A.A., Marcova L.V., Hamzeleva T.V ."Structure and properties of porous composite materials based on powders of aluminosilicates and basalt fiber"// collection of papers"Powder Metallurgy " vol. 41; p. 147-153.

3. Zybina A.D., Semchenko P. D., "Heat-resistant, high-strength and heat-resistant keramika"// Glass and ceramics. 1992. No. 7. p. 14-15

4. Popov R. Yu., Dyatlova E. M., Sergievich O. A., Kolontaeva T. V. "Influence of cyclic thermal loads on the structure and properties of ceramic materials of various phase composition"// Refractories and technical ceramics. 2020. No. 4-5. p. 14-21

5. Strelov K. K. "Structure and properties of refractories" M. Metallurgy. 1982. $208 \mathrm{~s}$

6. https://yandex.by/turbo/mineraly-kamni.ru/s/silikaty

7. Dzhigiris D. D., Makhova M. F. "Fundamentals of the production of basalt products" Moscow: Teploenergetika, 2002. $412 \mathrm{p}$

8. Kruchinin Yu. D., Belousov Yu. L.'Formation of spinelides in pyroxene glasses containing iron oxides"// Physics and chemistry of glass. 1976. Vol. 2. No. 4. pp. 242-246

9. Manylov M. S., Gutnikov S. I., Lipatov Ya. V., Gaitok K. V., Filimonov D. S., Lazo-ryak B. I. "Crystallization of basalt continuous fibers in the oxidizing atmosphere"// Physics and chemistry of glass. 2012. Vol. 38. No. 4. pp. 565-573

10. Gutnikov S.I., Manylov M.S., Lipatov Ya.V., Lazoryak B.I., Pokholok K.V. "Effect of the Reduction Treatment on the Basalt Continuous Fiber Crystallization Properties"//J. Non-Cryst. Solids. 2013. V. 368. P. 45-50 